\title{
INVESTIGATION OF TILT-ANGLED DELIVERY VALVE IN HYDRAULIC RAM - EXPERIMENT RESULTS
}

\author{
M. Suarda* \\ Mechanical Engineering Department, Faculty of Engineering, \\ University of Udayana, Badung-Bali, Indonesia \\ Doctoral Program of Engineering Science, University of Udayana, \\ Badung-Bali, Indonesia

\section{G. B. W. Kusuma, M. Sucipta and A. Ghurri} \\ Mechanical Engineering Department, Faculty of Engineering, \\ University of Udayana, Badung-Bali, Indonesia \\ *Corresponding Author Email: made.suarda@unud.ac.id
}

\begin{abstract}
This paper presents the experiment results of the cycle work and overall performance of a new design of delivery valve in hydraulic ram. A hydraulic ram comprises of two non-return valves. They are well known as waste and delivery valves. Both mechanism propagate water hammer in cycle work of the hydraulic ram. In early designs, the water flow phenomenon occurring in the hydraulic ram operating process must be fully recognized for further analysis. Therefore, a transparent acrylic material of a hydraulic ram model was utilized to simulate the flow pattern within the hydraulic ram. In this study, the water flow phenomenon was visualized experimentally using dyes injection method. Then, videos and pictures recorded using slow motion video camera for investigating the hydraulic ram working cycle. The transparent hydraulic ram model was the first time introduced. The results show that the delivery valve with tilt-angled of $60^{\circ}$ was the best design to produce the optimal performance of the pump system. The most stagnation point of the flow directed through the delivery valve orifice. The total efficiency of the hydraulic ram theoretically improved up to $24 \%$ by using the new model instead of the old one.
\end{abstract}

Keywords: Delivery valve, hydraulic ram, tilted-angle, visualization, working cycle.

Cite this Article: M. Suarda, I.G.B.W. Kusuma, M. Sucipta and A. Ghurri, Investigation of Tilt-Angled Delivery Valve in Hydraulic Ram - Experiment Results. International Journal of Mechanical Engineering and Technology 11(2), 2020, pp. 117-129.

https://iaeme.com/Home/issue/IJMET?Volume=11\&Issue $=2$ 


\section{INTRODUCTION}

Hydraulic rams are renewable devices to pump a fraction water up to a higher site. It is powered by hydropower [1]. Principally, it is based on the pressure surge force as a result of the sudden valve closure [2]. Moreover, the hydraulic ram system is very basic (Fig. 1), comprising of water supply and transmission pipe, hydraulic ram body, waste (or impulse) and delivery valves, and air chamber [3, 4]. Furthermore, It operates automatically and continuously [5]. Therefore, it is practically adaptable for producing and repairing at municipal level in developing countries [6]. The hydraulic ram performance be subject to on numerous parameters involving the head of the water supply and delivery, the pump components [7]. Its mechanism operates two non-return valves. They are well-known as waste and delivery valves. The both valves operation produce cycling work in the pump operation. Thus, they are a crucial element of the system, requiring more emphasis and optimization to enhance the hydraulic ram performance $[8,9]$.

At the beginning, the waste valve (e) remains opened, and the delivery valve (f) stays shut. The water in the drive pipe (c) begins to stream under the power of gravity and accelerated until its momentum proficient to induce the waste valve closure. The sudden closure of the waste valve triggers a water hammer that brings the pressure surge in the pump body (d), then, opens the delivery valve, and pushes a fraction water to move into the air vessel (g) then flowing through the transmission pipe (i) up to the reservoir (j). Meanwhile this water is being constrained tough through the transmission pipe, the pressure wave propagates back flow up the drive pipe toward the supply tank (a). It is causing a negative pressure taking place under the waste valve disk. During this period, when the pressure in the drive pipe diminishes, the delivery valve closes, and the flow terminated. Then, the waste valve pulls down by the gravity force of its weight to opened position again, permits the cycle to start again. A single cycle work supposed into four main phases: acceleration, compression, pumping, and recoil $[10,11,12]$.

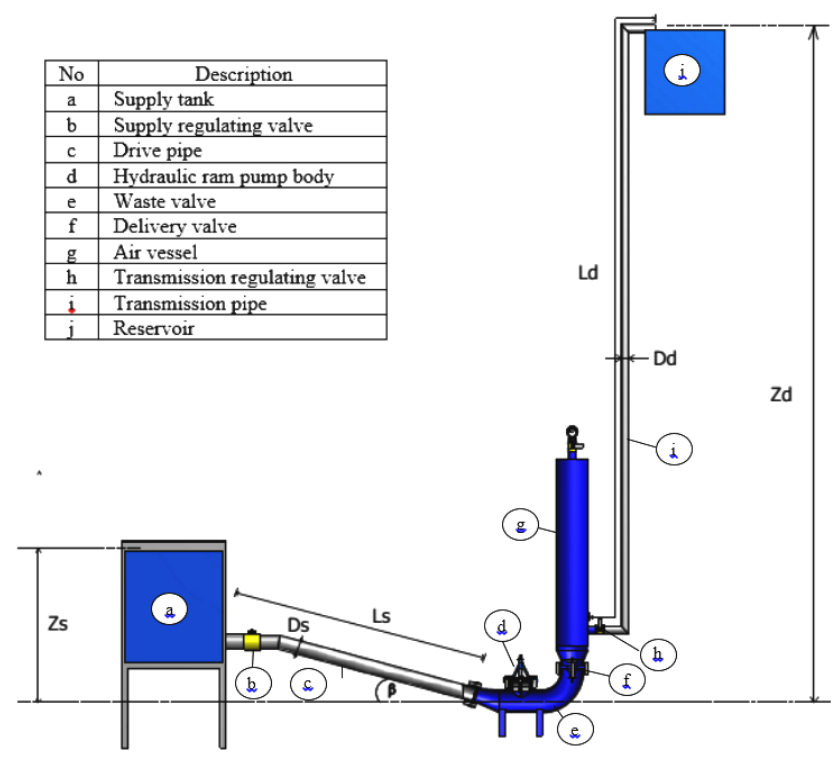

Figure 1. Schema of a hydraulic ram system

Different strategies can be utilized within the primary considerations of arranging and application [13]. Performance of the hydraulic ram was mainly influenced by the waste and the delivery valve [14]. An algebraic analysis can be used to study the forces that strike on 
both valves for evaluating of the valve weight design [15]. In addition, simple formula and procedure were recommended for approximating the optimum weight of the waste valve [16]. However, the valves have other parameters should be considered including diameter, mass and stroke. Altogether affect each other, then, impact the overall performance of the system. For instance, another work was conducted show that shortening the waste valve stroke increased the beats per minute of the cycle work and decreased the water supply flow rate in the drive pipe [17]. Further experiment work and numerical simulation have been developed on hydraulic ram model in determining the optimal efficiency. The results represented that the largest delivery flow is achieved at delivery head not exceed $50 \mathrm{~m}$ [18].

Recently, simulation methods using Computational Fluid Dynamics (CFD) preferred to experimental works subject to time and expenditure. The water flow phenomenon around a waste valve was simulated using Solid Work software [19]. Though, this simulation simply represented distribution of pressure and velocity but it was fault to identify the parameters that effected performance of the pump system. In addition, a new design of the waste valve was analyzed using simulation procedure which confirmed that a smaller quantity of water source flow rate passing through the new valve rather than the old one and offered improvement for its performance [20]. A Computer modelling and analysis can be conducted by considering several parameters design in determining the optimum solution [21]. Furthermore, the performance of hydraulic ram was analyzed using mathematical equations of the delivery head subject to the water flow rate delivered into reservoir [22]. The presented work developed regression equation for defining a mathematical relationship in order to determine the influence of the delivery head of the system. Further simulation work on a new design of the delivery and waste valve have been conducted by adding a controlled mechanism at the valves. This procedure claim that the new model enhanced efficiency of the hydraulic ram up to $20 \%$. In addition, modification design of the waste and delivery valves were conducted and analyzed by projected velocity vector and pressure contour [23, 24]. Indeed, the flow characteristic in the hydraulic ram has been performed and analyzed through simulation of hydraulic ram models using commercial CFD software. Some approaches and assumptions in determining the boundary conditions are taken. This of course affects the accuracy of the simulation results.

The flow pattern can be established experimentally using visualization methods including particle tracking or dye injection [25]. For instance, a closed-loop OHP is experimental inspection method to visualize an internal fluid flow pattern in pipe. The latest method, the working fluid uses a Pyrex glass with kerosene. Then, a high-speed video camera recorded the flow phenomena in the system [26]. After the invention of the hydraulic ram over 200 years ago, the water flow phenomenon in the pump remains does not well understanding. Therefore, these methods potentially applied in determining the water flow path and the working cycle of the hydraulic ram.

To the current decade, no one work has presented a real condition of flow pattern that actually occur in the hydraulic ram system. Hence, in this study, the flow pattern in hydraulic ram system was visualized experimentally using dyes injection procedure. Moreover, the components of the hydraulic ram system are constructed using a transparent acrylic material. This visualization work was introduced for the first time for investigating the flow patterns in the hydraulic ram system. Furthermore, a limited investigation and design development on the delivery valve were available in the literatures. Basically, the delivery valve models were flat shaped. The drawback of that models were a high shock losses takes place under the valve. Therefore, the aim of the present study was proposed a new model - tilt-angled - delivery valve in order to more focusing water flow into the orifice of the valve for enhancing the overall performance of the hydraulic ram. 


\section{RESEARCH METHODS}

\subsection{Experimental Setup}

In the present study, a hydraulic ram pumping system was made with acrylic (transparent) material so that the fluid flow which occurs within all components of the hydraulic ram could be seen. The experimental tests were conducted on a hydraulic ram installation scheme as presented in Fig. 2. While, the Fig. 3 show the hydraulic ram pump test model. It consists of a water supply tank (a), an overflow system (b) for remaining the water level in the tank at constant, supply regulating valve (c), flow meter (d), drive pipe (e), hydraulic ram body (f), waste valve (g), delivery valve (h), air vessel (i), transmission regulating valve (j), transmission pipe $(\mathrm{k})$, reservoir $(\mathrm{l})$, equipped with video camera $(\mathrm{m})$ which has a frame rate of $960 \mathrm{fps}$ and lighting (h). In addition, the water were mixed with paint particles (glitter) for identifying the flow path and its direction, displacement of the waste and delivery valves' disk.

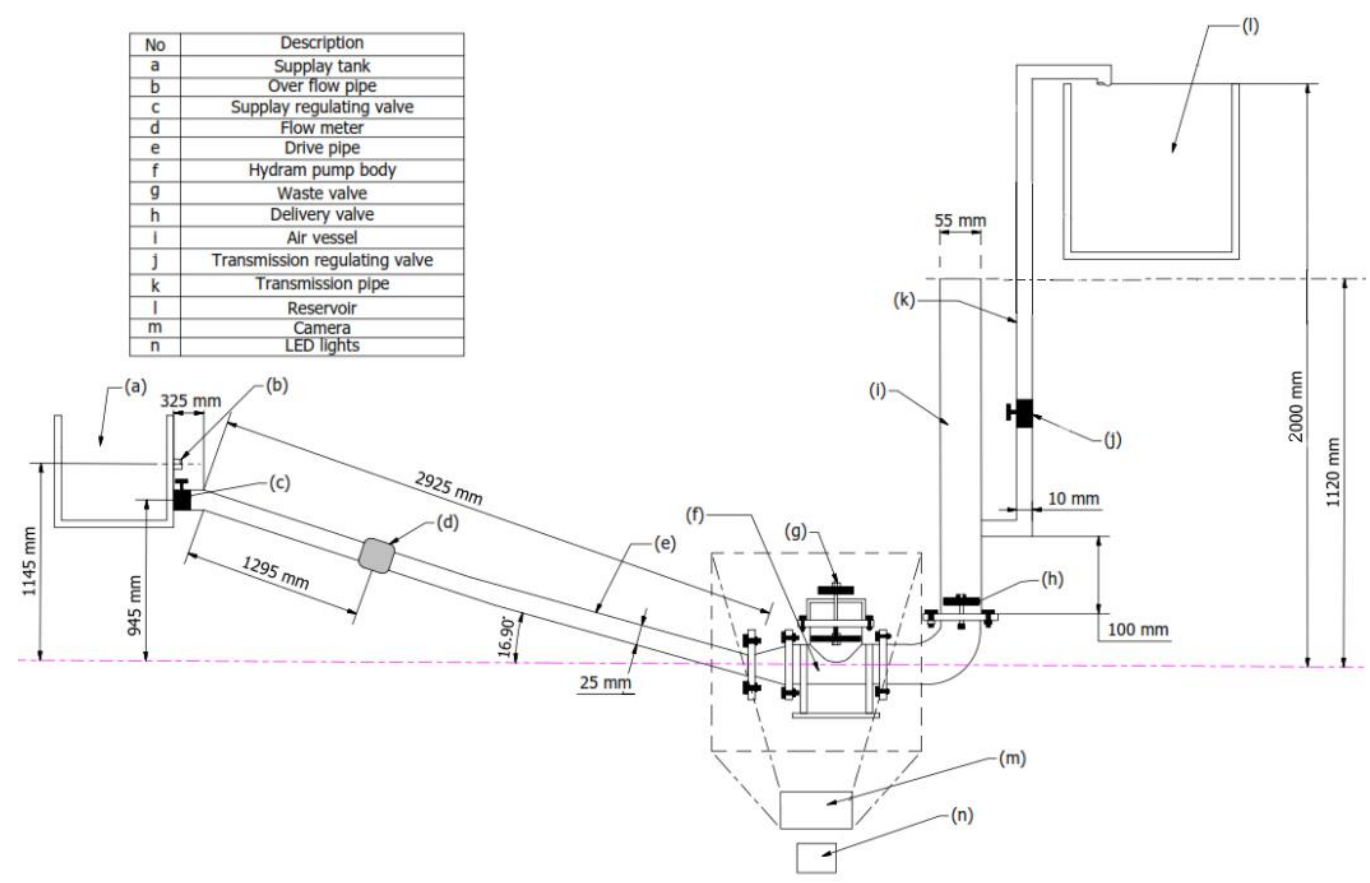

Figure 2. Installation arrangement of the hydraulic ram.

Specifications of the hydraulic ram model were: the drive pipe diameter $\left(D_{s}\right)$ of $25 \mathrm{~mm}$; delivery pipe diameter $\left(\mathrm{D}_{\mathrm{d}}\right)$ of $10 \mathrm{~mm}$; the diameter of hydraulic ram body and its air vessel of $55 \mathrm{~mm}$ with volume of $0.0083 \mathrm{~m}^{3}$. The waste has orifice diameter of $32 \mathrm{~mm}$ with disk diameter of $42 \mathrm{~mm}$, the moving parts mass of 100 gram and its stroke of $5 \mathrm{~mm}$. In the other hand, the delivery valve models were varied as in Fig. 4 and Table 1. The old model (flat) and the new models (tilt-angled of $45^{\circ}, 60^{\circ}$ and $75^{\circ}$ ) have the same dimension of their moving parts and orifice. The moving parts of the valve have disk diameter of $42 \mathrm{~mm}$ with the mass of 50 gram and its stroke of $5 \mathrm{~mm}$. Its orifice has 8 holes with diameter of $8 \mathrm{~mm}$. 


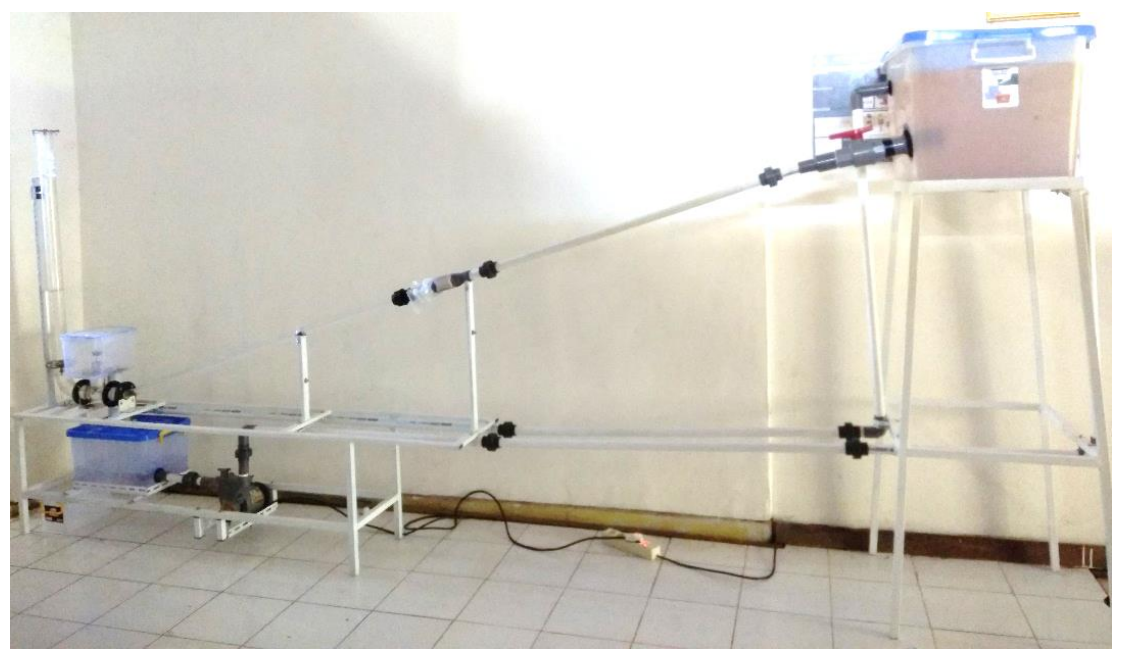

Figure 3. Experimental arrangement of the hydraulic ram

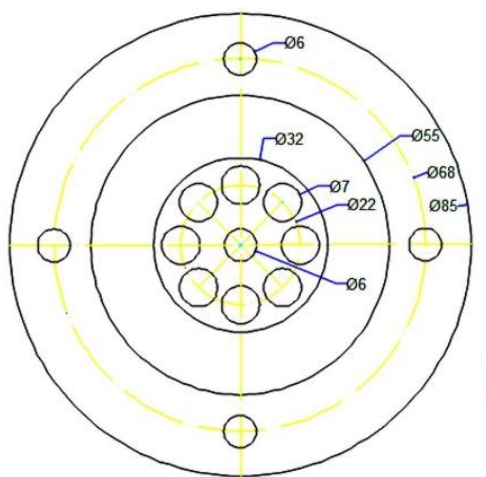

(a)

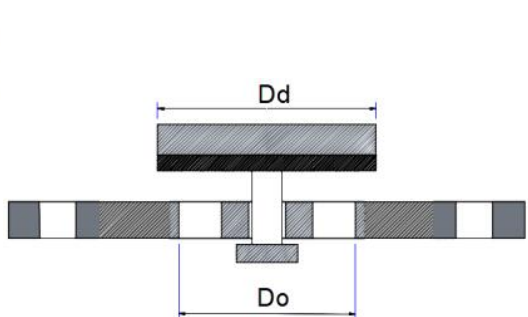

(b)

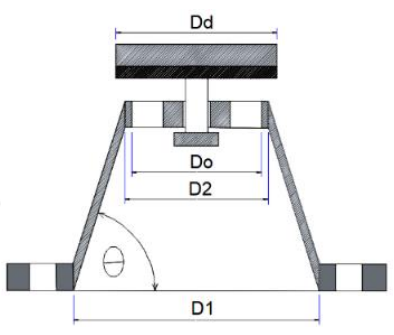

(c)

Figure 4. Delivery valve models: (a) top view, (b) flat model, (c) tilt-angled model

Table 1. The delivery valve models

\begin{tabular}{cccccc}
\hline Model & $\begin{array}{c}\text { Tilt } \\
\text { angle, } \boldsymbol{\theta} \\
\left({ }^{\circ}\right)\end{array}$ & $\begin{array}{c}\text { Orifice } \\
\text { peripheral } \\
\text { diameter, Do } \\
(\mathbf{m m})\end{array}$ & $\begin{array}{c}\text { Valve disc } \\
\text { diameter, } \mathbf{D}_{\mathbf{d}} \\
(\mathbf{m m})\end{array}$ & $\begin{array}{c}\text { Bottom } \\
\text { chamber } \\
\text { diameter, } \mathbf{D}_{\mathbf{1}} \\
(\mathbf{m m})\end{array}$ & $\begin{array}{c}\text { Bottom } \\
\text { chamber } \\
\text { diameter, } \mathbf{D}_{\mathbf{2}} \\
(\mathbf{m m})\end{array}$ \\
\hline DV-0 & 0 (flat) & 28 & 42 & 32 & 55 \\
DV-45 & 45 & 28 & 42 & 32 & 55 \\
DV-60 & 60 & 28 & 42 & 32 & 55 \\
DV-75 & 75 & 28 & 42 & 32 & 55 \\
\hline
\end{tabular}

\subsection{Experimental Procedure}

The flow visualization in the hydraulic ram model were using a media in the form of paint particles which was sprayed by an injection syringe, so that the flow pattern could be seen clearly and recorded employing a high-speed digital video camera. The camera was Sony RX100-IV which has 960 fps (frames per second). Then, the slow motion video converted into images/frames using Video-Jpg Converter. The video was recorded in 2.07 seconds then it was extracted into 2070 images. The valve movements and flow direction were traced from the frames. Next, from the pictures, the distance of the valves movement and their time periods were measured using Image-J software. The length of the trip of a single particle was 
measured, then divided by the shutter speed of the camera. In this study the shutter speed was fixed on 0.001 seconds.

Moreover, a V-notch weir was utilized for measuring the average water flow rate out from the waste valve. The discharge equation is

$$
Q=C_{d} \frac{18}{15} \sqrt{2 g} \cdot \tan \left(\frac{\theta}{2}\right)\left(h_{v}\right)^{5 / 2}
$$

Where $\mathrm{Q}$ is the fluid flow rate $\left(\mathrm{m}^{3} / \mathrm{s}\right), \mathrm{C}_{d}$ is the flow coefficient, $\theta$ is the V-notch weir angle, $h_{v}$ is the fluid flow level through $\mathrm{V}$-notch weir $(\mathrm{m})$, and $\mathrm{g}$ is the gravity acceleration $\left(\mathrm{m} / \mathrm{s}^{2}\right)$. The V-notch weir was calibrated using a laboratory measurement cup having a volume of 5 litters (the error of the volume measurement was 1\%) and a timer, yield $\mathrm{C}_{\mathrm{d}}$ of 7.2266.

Then, the total efficiency of the hydraulic ram system $\left(\eta_{\mathrm{R}}\right)$ was using the Rankine method:

$$
\eta_{R}=\frac{Q_{d} H_{d}}{\left(Q_{d}+Q_{w}\right) H_{s}} 100 \%
$$

Where $\mathrm{Q}_{\mathrm{w}}$ is the waste water outflow $\left(\mathrm{m}^{3} / \mathrm{s}\right), \mathrm{Q}_{\mathrm{d}}$ is the delivery water flow rate $\left(\mathrm{m}^{3} / \mathrm{s}\right), \mathrm{H}_{\mathrm{s}}$ is the supply head $(\mathrm{m})$, and $\mathrm{H}_{\mathrm{d}}$ is the delivery head $(\mathrm{m})$.

\section{RESULTS AND DISCUSSIONS}

Based on the images of video extraction and particles trace, the water flow in the hydraulic ram had been visualize at each step in a single cycle work. Meanwhile, both of the waste and delivery valves displacement were determined along of the working cycles. In addition, measurements of quantity of water flow out from the waste and delivery valves were obtained. Then, further investigation was accomplished to determine the effect of changes in the tilt angle of the delivery valve. The flat plate (tilt angle of $0^{\circ}$ ) of delivery valve seat model was used as a reference in the comparison.

\subsection{The Flow Pattern in the Working Cycle of the Hydraulic Ram}

The displacement and direction of a particle was carried out at four steps of the hydraulic ram working cycle, namely from the acceleration, compression, delivery and recoil cycles. Four images that have been selected in each variation of the delivery valve. The first stage is the acceleration step, where the waste valve remains to open and the delivery valve keeps on closure. The water source streamed in the drive pipe entering the pump body flowing out through the waste valve, as in Fig. 5(a). The red path-line show that the driving water flowed through the bottom side of the pump inlet, then turned toward the waste valve orifice. Therefore, the drive pipe suggested to make a slope with ratio of $\mathrm{H}_{\mathrm{s}} / \mathrm{Ld}_{\mathrm{d}} \cong 4$ to 8 . A fraction of them circulated at top side of the bend pump body, then turned to the bottom of the bend (yellow path-line) because of the flow was blocked as a results of the delivery valve in closure. Eddy currents (green path-line) take places at the top inlet side and the bottom of outside of the pump body.

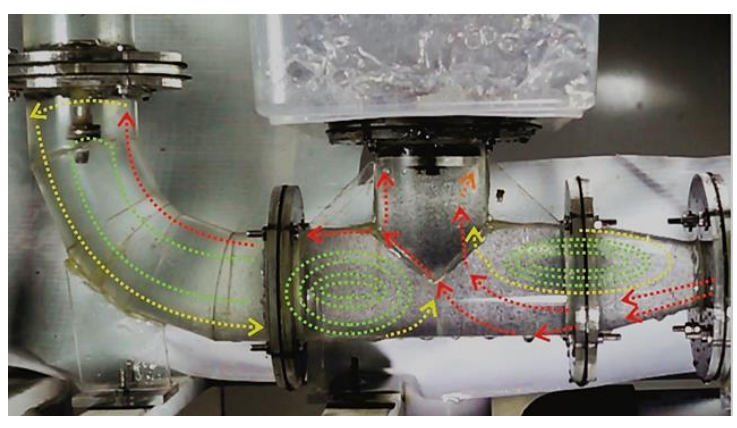

(a) acceleration

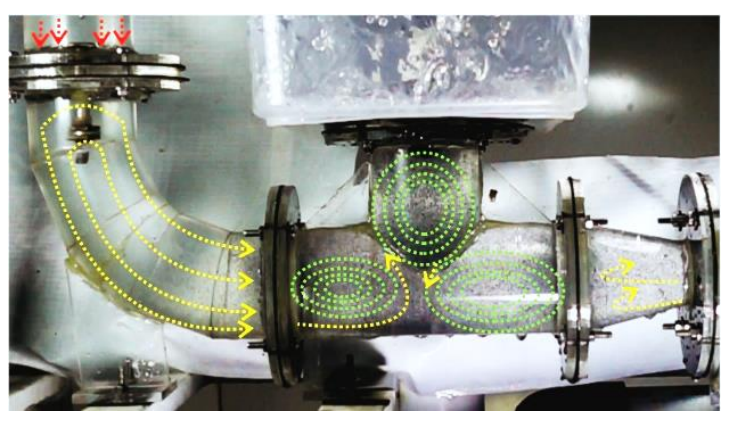

(b) compression 


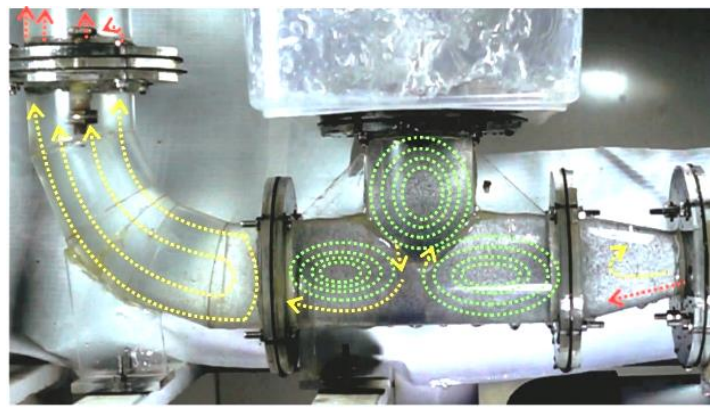

(c) delivery

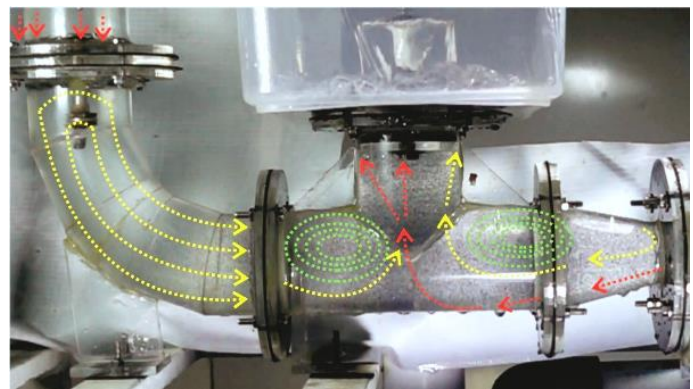

(d) recoil

Figure 5. The flow pattern in the cycle phase of hydraulic ram.

When the waste valve closed suddenly because of momentum change have enough impulse force to against the weight force of the valve, the water has been ready in the pump body was compressed, as shown in Fig. 5(b). Because of the flow in blocked circumstance they generated eddy currents (green line) at each end side of the pump body (tee form). Meanwhile, the compressed water under the delivery valve (in closure position) tend to push back toward the drive pipe and was causing a back flow (yellow path-line). This process occurred in very short time, then, the high pressure in the pump chamber, higher than the pressure in the air vessel, made the delivery valve opened, and the delivery (pumping) phase happened. A fraction of the water flowed up (yellow path-line) across the delivery valve into the air vessel then transmitted throughout the delivery pipeline, as shown in Fig. 5(c). Temporarily, some water was still under eddy current (green path-line) in the pump chamber. Subsequently, the delivery valve was going to closure owing to the pressure under the pressure under the delivery valve lower that pressure in air vessel. This was causing blocked flow (yellow path-line) under the valve and intent to back toward the pump chamber, as shown in Fig. 5(d), and recoil phase take place in very short time. Finally, the pumping and the back flows created a low pressure under the waste valve disk, hence the valve fall to open by its weight gravity force, and the cycle work repeated.

Moreover, the velocity of flow water in the hydraulic ram could be determined by tracking a specific particle of the added glitter. For example, the water flow velocity was passing through the delivery valve, in case of the delivery valve with tilted angle of $60^{\circ}$, at about 2.6 $\mathrm{m} / \mathrm{s}$. The tilted angle of the delivery valve chamber affected the flow velocity through the valve. Although the flow velocity passes through underneath of the delivery valve with the flat plate model was the highest but the flow velocity at immediate prior and subsequent to the delivery valve disk is the lowest. This is due to the large amount of flow strikes the delivery valve mounting plate. This indicates that the stagnation point is less coincided towards the delivery valve outflow orifice.

\subsection{The Valves Displacement in the Working Cycle of the Hydraulic Ram}

The cycle period and frequency of the hydraulic ram was identified from the frames that were extracted from the videos. For single cycle, the initial cycle commenced when the waste valve disk immediately attained its full opened position, as presented in Fig. 6(a), and completed when the disk immediately start to open from its full close position, as shown in Fig. 6(b). Because of the frame rate of the video was $960 \mathrm{fps}$, therefore each frame spend 1/960 second. The investigation results of displacement of the waste and delivery valve steps of a single working cycle for the four model of the delivery valve that were inspected were presented in Table 2. 


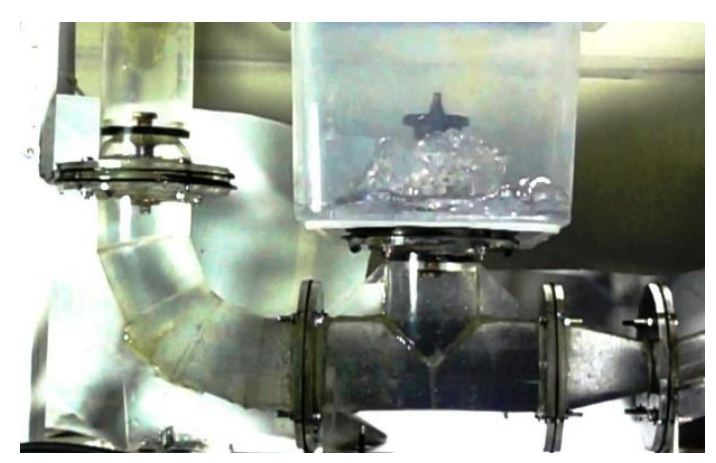

(a)

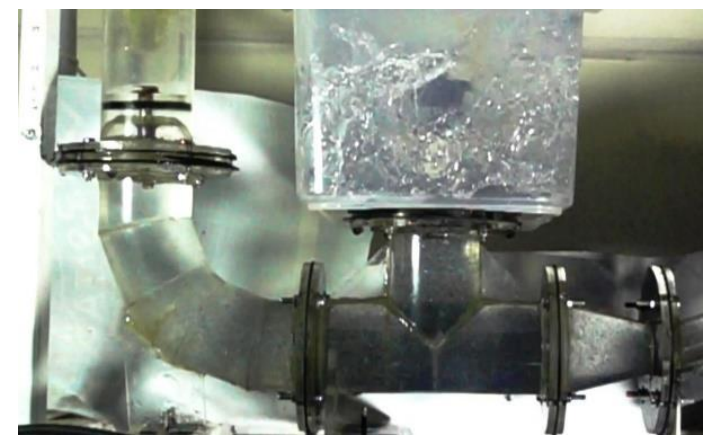

(b)

Figure 6. View of the valves position: (a) the waste valve full opened and the delivery valve full closed, (b) the waste valve full closed and the delivery valve full opened

Table 2 shows the data of the displacement steps of the waste and delivery valves on the variation of the delivery valve. Model DV-0 is the delivery valve with the tilt angle of the delivery valve housing $0^{\circ}$ or flat, Model DV-45 is at tilt angle of $45^{\circ}$, Model DV-60 is at tilt angle of $60^{\circ}$, and Model DV-75 is at tilt angle of $75^{\circ}$. The waste valve (WV) go through fourstep sequence of movements that are fully open (WV_FO) at the acceleration stage of the water flow out through the waste valve which drives the pump. Then, during the change in flow momentum is able to move the waste valve from the open position to the closed (WP_OC), the pressure in the pump body increase sharply due to the closure of the waste valve suddenly. This high pressure forces the delivery valve (DV) moving from full closed position (DV_FC) to open position (DV_C-O). As long as the delivery valve in the fully open position (DV_FO) occurs a flow of water from the pump body into the air vessel and then flows across the delivery pipe into the reservoir. At the same time, the water in the pump body flows return to the drive pipe. As a result, the pressure inside the pump body decreases initiating the waste valve drops back again (WV_C-O) due to gravity force. Next, the delivery valve moves to close again (DV_O-C), and then the hydraulic ram working cycle is repeated.

Table 2. Displacement of the waste and delivery valve steps at variation of the tilted angle of the delivery valve.

\begin{tabular}{cccccc}
\hline & & \multicolumn{4}{c}{ Model } \\
\cline { 3 - 6 } & & DV-0 & DV-45 & DV-60 & DV-75 \\
\hline 1-cycle & (frame) & 813 & 857 & 881 & 870 \\
Period, $\mathrm{T}_{\mathrm{c}}$ & $($ second) & 0.847 & 0.893 & 0.918 & 0.906 \\
Frequency & $($ beats/min) & 70.85 & 67.21 & 65.38 & 66.21 \\
WV_FO & $\left(\% \mathrm{~T}_{\mathrm{c}}\right)$ & 60.394 & 63.244 & 65.267 & 63.908 \\
WV_O-C & $\left(\% \mathrm{~T}_{\mathrm{c}}\right)$ & 9.717 & 8.401 & 7.378 & 6.897 \\
WV_FC & $\left(\% \mathrm{~T}_{\mathrm{c}}\right)$ & 19.188 & 20.887 & 20.318 & 20.345 \\
WV_C-O & $\left(\% \mathrm{~T}_{\mathrm{c}}\right)$ & 10.701 & 7.468 & 7.037 & 8.851 \\
DV_FC & $\left(\% \mathrm{~T}_{\mathrm{c}}\right)$ & 79.705 & 80.280 & 81.385 & 80.690 \\
DV_C-O & $\left(\% \mathrm{~T}_{\mathrm{c}}\right)$ & 1.968 & 1.050 & 0.908 & 0.920 \\
DV_FO & $\left(\% \mathrm{~T}_{\mathrm{c}}\right)$ & 9.102 & 12.835 & 13.394 & 13.678 \\
DV_O-C & $\left(\% \mathrm{~T}_{\mathrm{c}}\right)$ & 9.225 & 5.834 & 4.313 & 4.713 \\
\hline
\end{tabular}

1 second $=960$ frames 


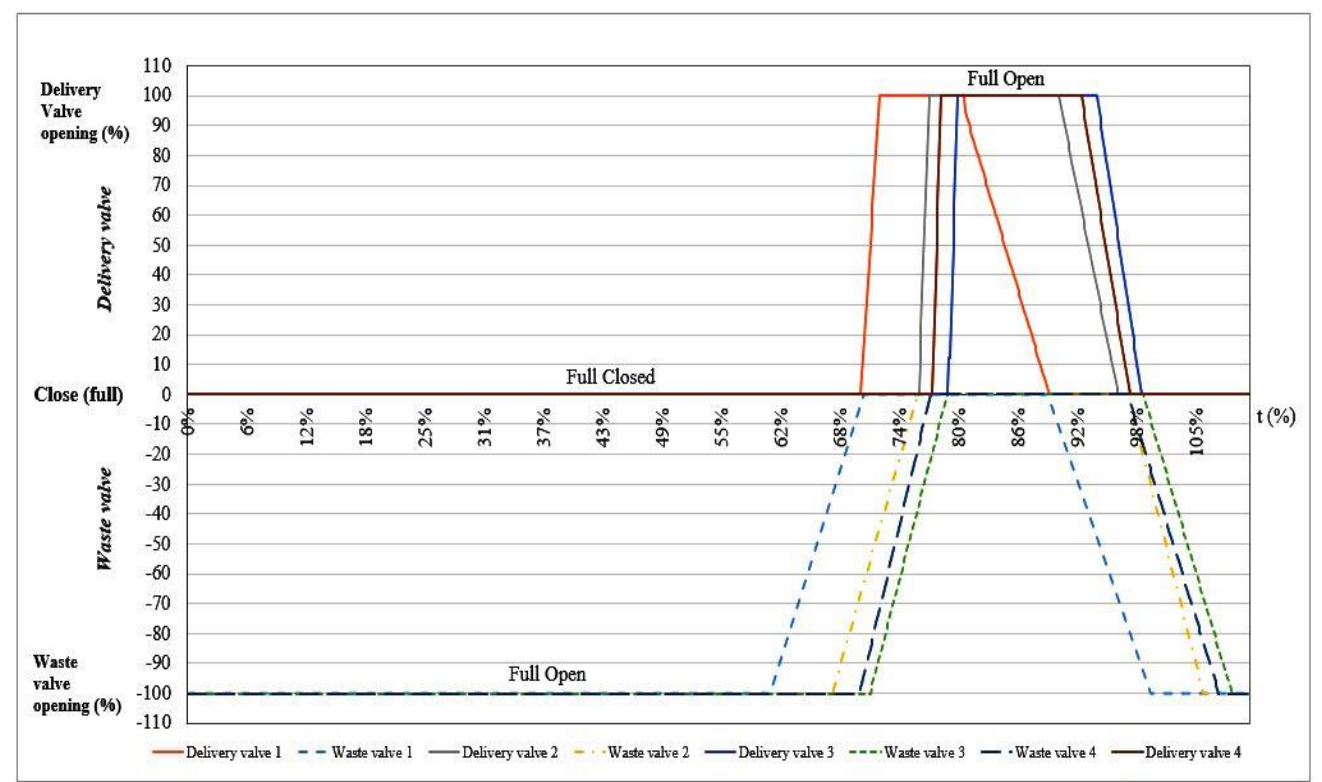

Figure 7. Valve stroke in the hydraulic ram working cycle.

According to Table 2, it was illustrated the stroke steps of the hydraulic ram working cycle, as in Figure 7. In this analysis, the flat plate model of the delivery valve housing (tilted angle $0^{\circ}$ ) is used as a basis for comparison. The conventional delivery valve with tilted angle $0^{\circ}$ has the shortest working cycle period at around 0.847 seconds with a frequency approximately 71 beats/minute. In one working cycle, the delivery valve experienced a full closed position for 79.7\% of the cycle period $\left(\mathrm{T}_{\mathrm{c}}\right)$ and an open position of around $20.3 \%$ of the cycle period. The delivery valve with its valve seat housing has a tilted angle of $45^{\circ}$ and $75^{\circ}$ have a higher work cycle period compared to the flat plate $\left(0^{\circ}\right)$ model, that are about 0.893 seconds with a frequency of about 67 beats/minute and about 0.906 seconds with a frequency of about 66 beats/minute, respectively. The delivery valves with tilted angles of $45^{\circ}$ and $75^{\circ}$ were experienced a period of the fully closed valve position were nearly similar at $80.3 \%$ and $80.7 \%$ of the cycle period, and the open position were around $19.7 \%$ and $19.3 \%$ of the cycle period. Furthermore, the delivery valve housing with tilted angle of $60^{\circ}$ was resulting in the highest working cycle period of about 0.918 seconds with a frequency of about 65 beats/minute. Moreover, this valve model faced the highest full closed valve position which is around $81.4 \%$ and the open position was about $18.6 \%$ of the cycle period. Hence, from the valve displacement perspective, the delivery valve with the tilted angle of $60^{\circ}$ was the best alternative design.

Furthermore, the characteristic of the cycle work results were compared to other works. The single cycle periods were in good agreement with Rennie \& Bunt experimental results [27] and Filipan et al. simulation results [28] which were in the range of 0.75 up to 1.1 seconds. In addition, the frequency of the cycles were in great conformity with the measurement results by Rennie \& Bunt [27] and Alkouhi et al. [29]. According to Rennie \& Bunt, the frequencies were between 55 and 80 beats/min, and Alkouhi et al. presented in a wide range of 40 up to 155 beats/min. Next, the head position of the waste and delivery valves for the one complete working cycle were concurrent to the measurement results which were reported by Sobieski et al. [12]. The acceleration stage was about $65 \%$ of $\mathrm{T}_{\mathrm{c}}$, followed by compression, delivery and recoil were around $8 \%, 20 \%$, and $7 \%$ of $\mathrm{T}_{\mathrm{c}}$, respectively. Although their cycle period was very short, $290 \mathrm{~ms}$, as a results of the waste and delivery valves were using flap poppet check-valves which are available in the market. 


\subsection{The Hydraulic Ram Performance}

The hydraulic ram performance consists of the quantity of the driving water flow rate $\left(\mathrm{Q}_{\mathrm{s}}\right)$, pumping water discharge $\left(\mathrm{Q}_{\mathrm{d}}\right)$ and the total efficiency $(\mathrm{Eta})$. The performance of the hydraulic ram model on the variations of the tilted angle of delivery valve housing, as presented in Fig. 8 and 9 . The delivery valve house with the tilted angle of $60^{\circ}$ produced the largest pumping discharge and a lowest water supply flow needed to drive the pump, consequently it provided the highest total efficiency. As a result, the delivery valve with the tilt angled housing of $60^{\circ}$ was the best design to produce the optimum performance. Though, in this experiment, the restriction of the pressures work of the waste valve was limited due to the physical strength limitation of the acrylic material that was used to construct the hydraulic ram model.

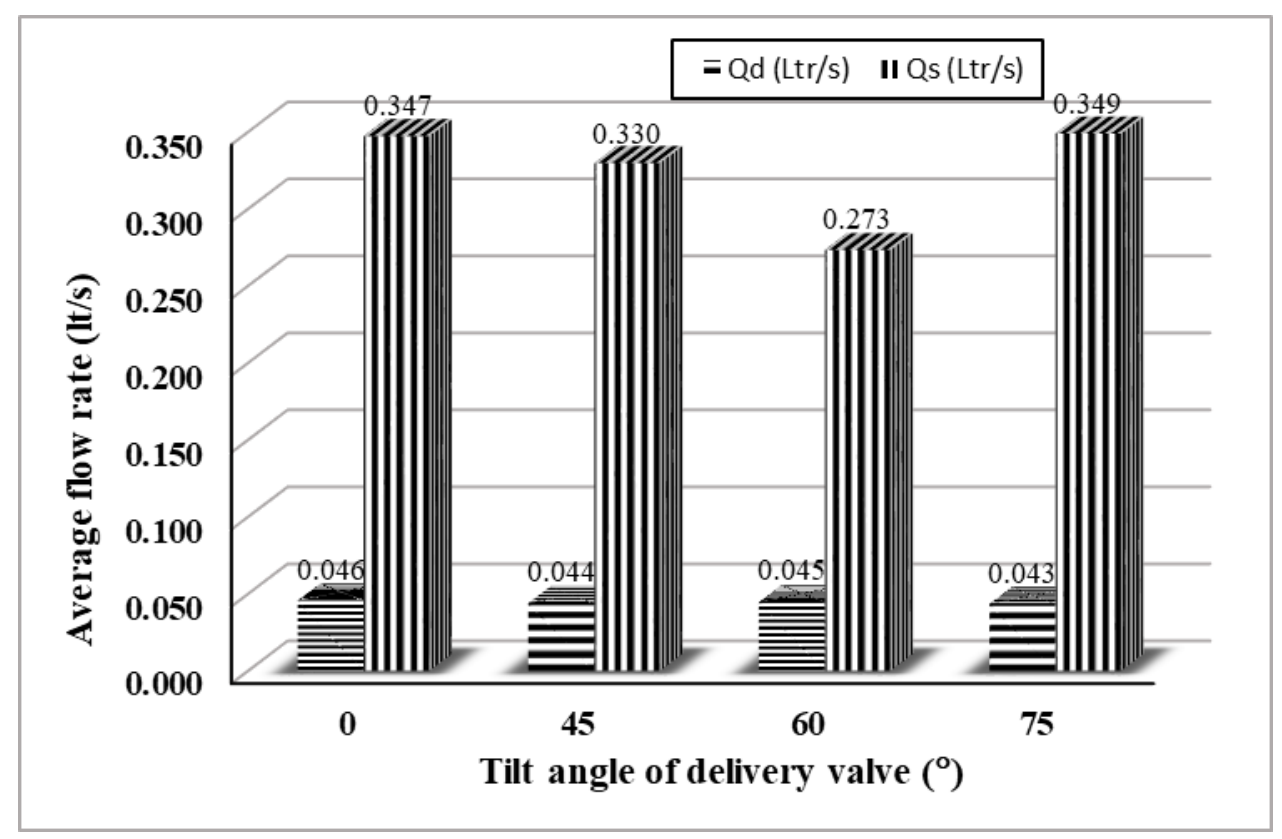

Figure 8. Discharge of water flow in the hydraulic ram.

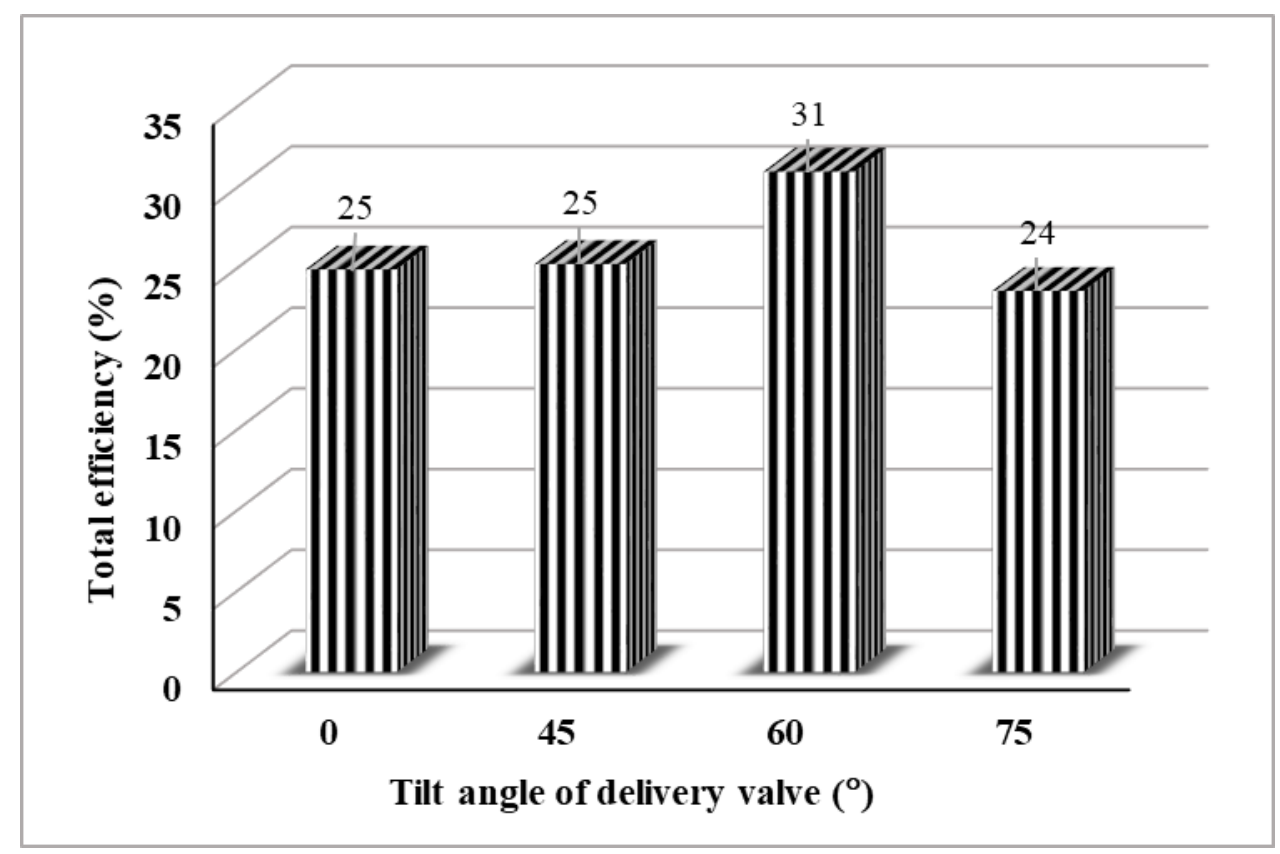

Figure 9. Total efficiency of the hydraulic ram. 
Further comparison of the overall performance were accomplished to other works. The portion of the waste water and delivery flow rates were in comparative to the other published works involved Rennie \& Bunt experimental results [27], Filipan et al. simulation results [28] and Alkouhi et al. measurement results [29]. However, the both flow rates are varied depend on the hydraulic ram dimension. The total efficiency of the presented work was quiet low because of the experimental apparatus was setup at short delivery head for the material constraint, even lower than Rennie \& Bunt results which were using an industrial product of hydraulic ram, Blake's Hydram. Nevertheless, this efficiency was agreeing with Filipan and Alkouhi results.

Considering of fluid flow indicators involved the flow pattern and the overall performance results show that the delivery valve housing with tilted angle of $60^{\circ}$ provide the optimal hydraulic ram performance. The stagnation point of the flow through the delivery valve orifice was the greatest focused in the design with an angle of $60^{\circ}$. Therefore, it is recommended that in its implementation to use the new design of the delivery valve with the tilted angle of $60^{\circ}$ instead of the conventional designs in the form of flat plates.

\section{CONCLUSION}

The water flow pattern can be registered using dye injection and high speed digital video camera in a transparent material of the hydraulic ram system. The nature of the results attained is adequate to interpret the phenomenon which takes place in the hydraulic ram operation. The research assisted in providing diagrams of the head position of the waste and delivery valves for each stage of a single hydraulic ram working cycle. The diagrams are in a good agreement with the work reported by Sobieski et al. [12]. In addition, the overall performance of the presented work is within the range of the results that provided by Rennie $\&$ Bunt [27], Filipan et al. [28], and Alkouhi et al. [29]. Furthermore, the experiment results show that the delivery valve chamber with tilted angle of $60^{\circ}$ is the best design to produce the optimum hydraulic ram pump performance. The new model provided total efficiency of $6 \%$ higher than the conventional one from $25 \%$ to $31 \%$, therefore the system's efficiency is theoretically improved by $24 \%$. Indeed, this real visualization results are fascinating and not yet available in the literatures. The flow characteristics are useful as consideration for further work for instance in simulation and numeric study.

\section{REFERENCES}

[1] G. Viccione, N. Immediata, R. Cava, and M. Piantedosi. 2018. A preliminary laboratory investigation of a hydraulic ram pump. MDPI Proceeding. The 3rd EWaS International Conference on "Insights on the Water-Energy-Food Nexus", Lefkada Island, Greece, 2730 June 2018. pp. 1-7.

[2] M.S. Ghidaoui, M. Zhao, D.A. McInnis, and D.H. Axworthy. 2005. A review of water hammer theory and practice. Transaction ASME: Applied Mechanics Reviews, January 2005, 58: 49-76.

[3] P. Diwan, A. Patel, and L. Sahu. 2016. Design and fabrication of hydraulic ram with methods of improving efficiency. International Journal of Current Engineering and Scientific Research (IJCESR). 3(4): 5-13.

[4] F.S. Januddi, M.M. Huzni, M.S. Effendy, A. Bakri, Z. Mohammad, and Z. Ismail. 2018. Development and testing of hydraulic ram pump (hydram): experiments and simulations. The Internacalvertional Fundamentum Sciences Symposium 2018. IOP Conf. Series: Materials Science and Engineering 440(2018) 012032. 
[5] M. Logesh, P. Sakthivel, K.L. Sibi, and R. Siva. 2018. Renewable energy hydram - a review. First International Conference on NexGen Technologies, Namakkal Dist. Tamilnadu-India, 5-6 January 2018: 679-681. ISBN: 978-93-86171-90-0.

[6] M. Inthachot, S. Saehaeng, J.F.J. Max, J. Müllerc, and W. Spreer. 2015. Hydraulic ram pumps for irrigation in Northern Thailand. Elsevier B.V: in Agriculture and Agricultural Science Procedia 5(2015): 107-114.

[7] A Pathak, A. Deo, S. Khune, S. Mehroliya S, and M.M. Pawar. 2016. Design of hydraulic ram pump. International Journal for Innovative Research in Science \& Technology 2(10): 290-293.

[8] A Pathak, A. Deo, S. Khune, S. Mehroliya S, and M.M. Pawar. 2016. Design methodology for hydraulic ram pump. International Journal for Innovative Research in Science \& Technology 5(4): 4737- 4745.

[9] P. Nambiar, A. Shetty, A. Thatte, S. Lonkar, and V. Jokhi. 2015. Hydraulic ram pump maximizing efficiency. International Conference on Technologies for Sustainable Development (ICTSD), 4-6 Feb. 2015, Mumbai - India. Published by IEEE.

[10] M.P. O'Brien, and J.E. Gosline. 1933. The hydraulic ram. University of California Press.

[11] P.O. Kahangire. 1984. The theory and design of the automatic hydraulic ram pump. Proceeding of a Workshop on Hydraulic Ram Pump (Hydram) Technology. Feb 1986. International Development Research Centre. Canada.

[12] W. Sobieski, D. Grygo, and S. Lipinski. 2016. Measurement and analysis of the water hammer in ram pump. Indian Academy of Science: Sadhana 41(11): 1333-1347.

[13] R.D. Balguda, S.P. Rupanavar, P.S. Bagul, and M.R. Ramteke. 2015. Designing of hydraulic ram pump. International Journal of Engineering and Computer Science. 4(5): 11966-11971.

[14] K. Yang, J. Li, Y. Guo, X. Guo, and H. Fu. 2014. Design and hydraulic performance of a novel hydram. $11^{\text {th }}$ International Conference on Hydroinformatics. New York City, 8 January2014. Paper no. 108.

[15] M. Suarda. 2015. Force analysis on a spherical shaped delivery valve of hydraulic ram pump. Applied Mechanics and Materials, Trans Tech Publications Switzerland, 776( 2015): 377-383.

[16] M. Suarda, A. Ghurri, M. Sucipta, and I G.B.W. Kusuma. 2018. Investigation on characterization of waste valve to optimize the hydraulic ram pump performance. AIP Conference Proceedings 1984, 020023 (2018).

[17] S.S. Mondol. 2017. Design, manufacture and test a hydraulic ram. Research Gate Article, May 2017. https://www.researchgate.net/publication/317031378.

[18] X. Guo, J. Li, K. Yang, H. Fu, T. Wang, Y. Guo, Q. Xia, and W. Huang. 2018. Optimal design and performance analysis of hydraulic ram pump system. Proceeding of Institution of Mechanical Engineering 2018, Part A. J. Power and Energy 0(0): 1-15.

[19] Y.Y. Maw, and Z.M. Hte. 2014. Design of 15 meter head hydraulic ram pump. International Journal of Scientific Engineering and Technology Research 03(10): 21772181.

[20] P.B. Shende, S.K. Choudhary, and A.P. Ninawe. 2015. Analysis and enhancement of hydraulic ram pump using computational fluid dynamics (CFD). International Journal for Innovative Research in Science \& Technology. 2(3): 109-133. 
[21] S.S. Sampath, S. Shetty, A.M. Pendanathu, W. Javaid, and M.C.P. Selvan. 2015. Estimation of power and efficiency of hydraulic ram pump with re-circulation system. International Journal of Computer-aided Mechanical Design and Implementation. 1(1): 718.

[22] D. Grygo. 2016. Effect of the height of the delivery water on performance of water ram. Technical Sciences, University of Warmia and Mazury in Olsztyn. 19(2):139-149.

[23] M.N. Harith, R.A. Bakar, D. Ramasamy, and M. Quanjin. 2017. A significant effect on flow analysis \& simulation study of improve design hydraulic pump. $4^{\text {th }}$ International Conference on Mechanical Engineering Research (ICMER2017). IOP Conf. Series: Materials Science and Engineering 257(2017) 012076. doi:10.1088/1757899X/257/1/012076.

[24] M.N. Harith, R.A. Bakar, D. Ramasamy, K. Kardigama, and M. Quanjin. 2018. A study of waste and delivery valve design modification to the pump performance. iCITES 2018. IOP Conf. Series: Materials Science and Engineering 342(2018) 012090.

[25] H.K. Karadeniz, D. Kumlutas, and O. Ozer. 2013. Experimental visualization of the flow characteristics of the outflow of a split air conditioner indoor unit by meshed infrared thermography and stereo particle image velocimetry. Experimental Thermal and Fluid Science, Elsevier Inc. 44(): 334-344.

[26] H. Goshayeshi, and I. Chaer. 2013. Experimental study and flow visualization of fe2o3/kerosene in glass oscillating heat pipes. Applied Thermal Engineering, Elsevier Inc. 103():1213-1218.

[27] L.C. Rennie, and E.A. Bunt. 1990. The Automatic hydraulic ram - experimental results. Proceeding of Institution of Mechanical Engineers. 204: 23-31.

[28] V. Filipan, Z. Vireg, and A. Bergant. 2003. Mathematical modelling of a hydraulic ram pump system. Journal of Mechanical Engineering. Strojniski Vestnik. 49(3): 137-149.

[29] R.F. Alkouhi, B.L. Ara, and A. Keramat. 2019. On the measurement of ram-pump power by changing in water hammer pressure wave energy. Ain Shams Engineering Journal. 2090-4479(2019): 1-13. Production and hosting by Elsevier B.V. on behalf of Ain Shams University.

[30] Dmitriy Moldovan, Vladimir Chernobai, Natalia Koteleva, Entry Stability in Steeply Inclined Thick Coal Seam at Underground Hydraulic Mining, International Journal of Civil Engineering and Technology (IJCIET), 10(1), 2018, pp. 817-824

[31] Tung Nguyen Dinh, an Investigation of Lifting and Discharging Cassava Roots System Using Hydraulic Transmission, International Journal of Mechanical Engineering and Technology, 9(11), 2018, pp. 297-308

[32] G. Kalaiarasan, Giriraj Mannayee, Boopathi M, Somanadh Mayakoti and K. Krishnamurthy, Analysis of Hydraulics Actuator Speed Control Using Digital Hydraulics. International Journal of Mechanical Engineering and Technology, 8(7), 2017, pp. 213-224 